\title{
Experiências possíveis no âmbito da história oral: memórias da emancipação do município de Queimados - RJ ${ }^{1}$
}

\author{
Possible experiences within the oral history: \\ memories of the emancipation of the city of Queimados - RJ
}

\author{
Claudia Patrícia de Oliveira Costa
}

\begin{abstract}
Professora da rede estadual do Rio de Janeiro. Mestranda do Programa de Pós Graduação em História da Universidade do Estado do Rio de Janeiro (PPGH/Uerj) cliouerj@yahoo.it
\end{abstract}

\section{Nilson Henrique de Araujo Filho}

\author{
Especialista em História do Rio de Janeiro pela Universidade Federal Fluminense (UFF) \\ e professor das redes estadual e particular, no Rio de Janeiro \\ nhaf.nilson@bol.com.br
}

Resumo

As questões que envolvem as relações entre memória e história têm ocupado espaço significativo nos debates acadêmicos recentes, particularmente no contexto da renovação experimentada no campo da História Política. O caráter recente da emancipação da cidade de Queimados, na Baixada Fluminense, nos instiga a pensar possibilidades para a escrita dessa história identificando, nessa discussão, um terreno profícuo para um debate mais amplo sobre as vozes que defenderam a autonomia queimadense. Para isso, propomos o registro audiovisual e a posterior análise crítica das transcrições dos depoimentos colhidos das lideranças da Associação de Amigos para o Progresso de Queimados (AAPQ), entidade criada com o objetivo de organizar o movimento emancipacionista que culminou no plebiscito de 1990.

Palavras-chaves: Memórias - História Local - Queimados

\section{Abstract}

The relationship between memory and history have occupied significant space in recent scholarly debates, particularly in the context of the renewal of political history. The recent emancipation of the city of Queimados, in the Baixada Fluminense, leads us to think possibilities for writing this history, so identifying a fruitful ground for a wider debate about the voices that defended the autonomy queimadense. Thus we make the record audiovisual and subsequent critical analysis of the transcripts of the interviews conducted with the leaders of the Associação de Amigos para o Progresso de Queimados (AAPQ), an entity created for the purpose of organizing the emancipation movement that culminated in the 1990 plebiscite.

Keywords: Memories - Local History - Queimados

1 Texto apresentado sob forma de comunicação, durante o X Encontro Regional Sudeste de História Oral, no Simpósio Temático Diálogos Contemporâneos: fontes orais e visuais nas pesquisas sobre memória. 
O historiador português, Fernando Catroga, chama a atenção para a constante tensão entre memória e historiografia, argumentando que, durante muito tempo, verificou-se um esforço para demarcar as oposições entre essas duas esferas. Segundo essa perspectiva, a história se diferenciava da memória pelo seu caráter cientificista, buscando estabelecer parâmetros analíticos que solapassem as mistificações das recordações e distanciassem cada vez mais sujeito e objeto. Entretanto, como o próprio autor conclui, as questões que envolvem as relações entre memória e história têm se revelado muito mais complexas, extrapolando as oposições binárias entre emoção/razão, verossimilhança/realidade ou subjetividade/objetividade (CATROGA, 2001: 39-40). Ao longo do século passado, diversos trabalhos se constituíram como referenciais para discutir tais questões. Sob essa perspectiva, destaca-se a obra de Maurice Halbwachs, na qual este autor afirma que as memórias individuais são sempre permeadas pelo contexto social. A obra de Halbwachs, cuja primeira publicação remonta à primeira metade do século XX, opera uma interessante distinção entre o que o autor chama de memória histórica e memória coletiva. Para Halbwachs, enquanto a primeira se caracteriza pela artificialidade, assumindo uma função didático-social definida, a memória coletiva é espontânea e, intrinsecamente, ligada à oralidade, integrando, portanto, um repertório de memórias individuais, visando à perpetuação de valores ancestrais que mantivessem a coesão de dado grupo (HALBWACHS, 1990).

No avançar dos debates, já em fins do século XX, destacaram-se as contribuições expressas pelas pesquisas do historiador Pierre Nora (1984) e do sociólogo Michael Pollak (1989 e 1992). Partindo do referencial constituído pela obra de Halbwachs, esses autores procuraram aprofundar os estudos sobre as memórias e propor novas abordagens teórico-metodológicas para as questões que envolvem a intrincada relação entre memória e história. Enquanto Nora buscou, em sua análise, discutir a materialidade das memórias, apostando nas representações da história expressas em museus, monumentos e os chamados lugares de memória, Pollak procurou analisar os complexos trabalhos de enquadramento das memórias. ${ }^{1}$ Para o sociólogo austríaco, interessa avaliar as tensões e as disputas ocorridas antes que as memórias possam adquirir qualquer tipo de materialidade e, para isso, aposta na coleta e na análise de depoimentos orais. Ao debruçar sobre tais depoimentos, Pollak nos estimula a pensar sobre os recortes do passado operados pelas memórias, dando espaço para que se discuta a dimensão política da memória. Entendemos que tal perspectiva presume o individual e o coletivo como domínios que estão continuamente interpolados, o que nos aponta o valor das análises que problematizem essa dinâmica. Se, por um lado, questionam-se as relações de oposição entre memória e história, a partir das questões suscitadas por essas pesquisas ao final do século XX, entende-se como necessário o enfoque das memórias em sua dimensão mais conflituosa. Essa perspectiva implica que se reconheça a força da memória, não só na coesão de grupos, como no desmantelamento e na reconfiguração de coletividades, em um permanente esforço pela construção de identidades.

Dessa forma, inferimos que as discussões, que põem em questão as tensões entre memória e história, têm ocupado espaço significativo nos debates acadêmicos que adentraram o presente século, particularmente no contexto da renovação da História Política. Essa renovação, posta em curso ainda a partir da segunda metade do século XX, buscou distanciar-se das abordagens reconstrucionistas, que caracterizaram a História Política durante o século XIX. Assim, a História Política Renovada manifestou, entre outras tendências, a busca de abordagens pluridisciplinares, apontando novas possibilidades de interpretação do campo político, como nos indica a revalorização das narrativas, a partir da década de $1970 .^{2}$ A partir da ampliação das abordagens teórico-metodológicas, percebemos que essa revalorização das narrativas dialoga, intrinsecamente, com a adoção da História Oral como metodologia aplicada aos estudos históricos. A introdução da coleta de dados para pesquisa, extraída a partir da realização sistemática de entrevistas de campo, demarca uma aproximação significativa entre a história e a antropologia, como preconizara Pollak em seus referidos artigos. No mundo anglófono, essa aproximação remonta ainda a década de 1940, a partir da experiência da Universidade de Colúmbia em "gravar as memórias de personalidades importantes da história norte-americana" (THOMPSON, 1992: 89). Contudo, orientando-se pela própria dinâmica que permeou os debates historiográficos

1 "O trabalho de enquadramento da memória se alimenta do material fornecido pela história. Esse material pode sem dúvida ser interpretado e combinado a um sem-número de referências associadas; guiado pela preocupação não apenas de manter as fronteiras sociais, mas também de modificá-las, esse trabalho reinterpreta incessantemente o passado em função dos combates do presente e do futuro.” (POLLAK, 1989: 9)

2 Segundo Javier Gil Pujol, o chamado "retorno linguístico" (linguistic turn) se insere no contexto da reabilitação da História Política, em face do "fracasso ou esgotamento da prática historiográfica seguida pelos Annales e pela história marxista." Destacamos, todavia, que esse retorno à narrativa introduziu questionamentos e críticas, distanciando daquela perspectiva antiga, na qual a narrativa visava ao mero relato, tido como forma de revivificar o fato (PUJOL, 1983: 68-69). 
nas décadas subsequentes, os profícuos contatos entre história e antropologia logo buscaram dar conta de uma gama de novos objetos, que permaneciam excluídos ou invisíveis, mesmo depois das inovações introduzidas pelos Annales, carreados pelos pressupostos de uma abordagem social. Nesse sentido, ainda segundo o sociólogo britânico Paul Thompson:

A história oral (...) lança a vida para dentro da própria história e isso alarga seu campo de ação. Admite heróis vindos não só dentre os líderes, mas dentre a maioria desconhecida do povo. Estimula professores e alunos a se tornarem companheiros de trabalho. Traz a história para dentro da comunidade e extrai a história de dentro da comunidade. Ajuda os menos privilegiados, e especialmente os idosos, a conquistar dignidade e autoconfiança. Propicia contato - e, pois, a compreensão - entre classes sociais e entre gerações. E para cada um dos historiadores e outros que partilhem das mesmas intenções, ela pode dar um sentimento de pertencer a determinado lugar e a determinada época (THOMPSON, 1992: 44).

Ao refletir sobre a asserção de Thompson e as questões que envolvem memória e história, nosso trabalho propõe o registro audiovisual e a posterior análise crítica das transcrições de depoimentos colhidos dos moradores mais antigos da cidade de Queimados, na Baixada Fluminense. Levando em conta o caráter recente da emancipação queimadense, deparamos com precárias referências, no que tange os lugares de memória na cidade. Tal constatação levou-nos a apostar na possibilidade de pensar a escrita da história de Queimados a partir das vozes que defenderam sua autonomia. Essa abordagem busca analisar os trabalhos de enquadramento das memórias ainda em curso, mesmo decorridas pouco mais de duas décadas da conquista da autonomia política-administrativa desse município. De acordo com os pressupostos de Pollak, entrevemos que os processos que envolvem os enquadramentos das memórias podem ser lentos, pressupondo tanto continuidades quanto rupturas. Assim, inferimos que, para que se possam ser criados e reconhecidos os lugares de memória, é necessário que o enquadramento das memórias tenha sido responsável pela criação de um sentimento identitário, que agregue dada coletividade em torno de símbolos e lugares reconhecidos e referenciados pela maioria.

De tal forma, nossas pesquisas tiveram início a partir de depoimentos orais, que vêm sendo colhidos desde o ano de 2009 até a presente data. Nos últimos anos, no entanto, o enfoque recaiu sobre as lideranças da Associação de Amigos para o Progresso de Queimados (AAPQ), entidade criada com o objetivo de reorganizar o movimento emancipacionista após um plebiscito frustrado, por falta de quórum, em 1988. As ações da AAPQ foram significativas para dar representatividade ao movimento e organizar o plebiscito de 1990, que obteve a emancipação de Queimados. Para esse grupo mais restrito, que contou com oito líderes ${ }^{3}$, as entrevistas foram realizadas a partir do eixo de indagações atinentes à origem do depoente, seu engajamento político, Queimados como distrito, o movimento emancipacionista, argumentos mobilizados pró-emancipação, o fracasso do plebiscito de 1988, participantes da emancipação e Queimados emancipada. Uma vez cedido os direitos de uso de áudio e vídeo pelo próprio depoente, os registros são transcritos. Após a transcrição, aplicamos a esses textos uma leitura baseada na Análise do Discurso, como preconizada por Leonor Arfuch. Essa abordagem procura levar em conta as seguintes questões: a produção dialógica do sentido do diz̧er, as dificuldades da construção de um relato de vida; a análise das modalidades enunciativas, de forma que não as reduzam, nem tampouco as desestruturem; a polifonia ou a confrontação de vozes e relatos simultâneos, bem como a sensibilidade para perceber, nos hiatos, esquecimentos e silêncios, indícios relevantes para acessar as memórias do entrevistado (ARFUCH, 2010: 267).

Conformando essa abordagem ao trabalho de pesquisa desenvolvido no curso de Pós-Graduação em História (nível mestrado) da Universidade do Estado do Rio de Janeiro (PPGH/Uerj), sob a orientação da professora Márcia de Almeida Gonçalves, esboçamos a seguinte grade de análise dos documentos:

O enquadramento de cada uma das entrevistas, na grade esboçada acima, contribui significativamente para o cotejo das informações mobilizadas pelos depoentes. Dessa forma, busca-se equacionar a tensa relação entre a objetividade, exigência do discurso historiográfico, e as subjetividades, que são marcas incontestáveis do discurso oral.

A partir de então, as entrevistas são mobilizadas no sentido de analisar as elaborações de passado, operadas pelos depoentes em suas memórias. Com foco na defesa do ideal emancipacionista, os depoentes

3 Esses eram os oito líderes, ainda vivos, quando do começo desse trabalho: Carlos de França Vilela, Ismael Lopes de Oliveira, José Methódio Lima, Josias de Souza Mattos, Luiz Alonso Sanz, Luiz Gonzaga de Macedo, Maria de Fátima de Oliveira Barragán e Valtecir Gomes Leal. Dentre esses, José Methódio Lima já é falecido. 


\begin{tabular}{|l|l|l|l|l|l|}
\hline Emissor & $\begin{array}{l}\text { Local de fala do emissor } \\
\text { justificativa da escolha }\end{array}$ & Receptor & $\begin{array}{l}\text { Periodo/local em que foi } \\
\text { dado o depoimento }\end{array}$ & natureza do discurso & Transcritor e revisor \\
\hline Nome do depoente & $\begin{array}{l}\text { Enquadramento político-social } \\
\text { atual do depoente e como o } \\
\text { próprio define seu papel } \\
\text { nas lutas pela emancipação }\end{array}$ & $\begin{array}{l}\text { Para quem foi } \\
\text { concedida a } \\
\text { entrevista }\end{array}$ & $\begin{array}{l}\text { Data e local em que a } \\
\text { entrevista foi realizada }\end{array}$ & $\begin{array}{l}\text { Discurso oral } \\
\text { quem revisou o texto } \\
\text { da entrevista }\end{array}$ & \\
\hline
\end{tabular}

Categoria temática:

\begin{tabular}{|c|c|c|}
\hline Tema: & Enunciado: & Objetividade/Subjetividade \\
\hline $\begin{array}{l}\text { Assunto abordado pelo depoente } \\
\text { no trecho transcrito. } \\
\text { Para a analise do corpus documental } \\
\text { selecionado para essa pesquisa, foram } \\
\text { abordados os seguintes temas: origem } \\
\text { do depoente, Queimados como } \\
\text { distrito, engajamento político, } \\
\text { movimento emancipacionista, } \\
\text { argumentos pró emancipação e } \\
\text { Queimados emancipada }\end{array}$ & $\begin{array}{l}\text { Transcrição do trecho da entrevista, } \\
\text { na qual o depoente aborda tal tema }\end{array}$ & $\begin{array}{l}\text { A mensagem central, evidente na fala do depoente, em } \\
\text { diálogo direto com o contexto histórico em que ele se insere. } \\
\text { Igualmente, são observadas e analisadas as possibilidades } \\
\text { interpretativas para a fala do entrevistado, levando em conta } \\
\text { suas emoções, hesitações e deslizes, levando-se em conta } \\
\text { sua experiência pessoal evocada para narrar os epsódios } \\
\text { do movimento emancipacionista. As observações desse } \\
\text { campo proporcionam a reflexão sobre o diálogo entre } \\
\text { teoria e metodologia, a partir dos conceitos elaborados } \\
\text { por Michael Pollak, a saber: Memória Oficial e Memórias } \\
\text { Subterrâneas, enquadramento das memórias, silêncios, } \\
\text { esquecimentos e testemunhas autorizadas a narrar. }\end{array}$ \\
\hline
\end{tabular}

revelam quais aspectos do passado foram e são recortados com o objetivo de justificar a autonomia queimadense ante Nova Iguaçu. Reiterando que a construção das memórias é um trabalho que demanda uma intrínseca relação com a história, em um processo permanente de debates, disputas e negociações, inserimos essas falas em um contexto mais amplo, a saber: a gradual transição democrática brasileira, decorrida durante a década de 1980 e que, para alguns autores, ainda não se esgotou. ${ }^{4}$ Acreditamos que as lutas pelo retorno da democracia no Brasil, evidenciadas em movimentos como o "Diretas já!”, foram de grande importância para a emergência das reivindicações emancipacionistas em Queimados. Apropriando-se dos discursos que visavam à superação de um passado, dito opressor, a população queimadense passa a reivindicar, na década de 1980, sua desvinculação de Nova Iguaçu. Entre a frustração queimadense em 1988 e a consulta plebiscitária que resultou na emancipação em 1990, além da criação da AAPQ, ressaltamos a promulgação da Constituição Estadual do Rio de Janeiro, em 1989, bem como a elaboração da Lei Complementar Estadual $\mathrm{n}^{\circ}$ 59, em janeiro de 1990. A Lei Complementar Estadual $\mathrm{n}^{\circ} 59$ foi particularmente interessante, na medida em que alterou as exigências para a criação de novos municípios, incentivando a rearticulação do movimento emancipacionista em Queimados. ${ }^{5}$

4 Sobre o debate acerca da dinâmica que permeou o processo de abertura e democratização no Brasil, ver as teses na área da Ciência Política: AVRITZER, 1995; KERBAUY, 1999; ARTURI, 2001; KINZO, 2001; CODATO, 2005. Verifica-se, também, o recente interesse dos estudos históricos pelo tema, nas abordagens de AGGIO, 1996; CARVALHO, 2001; FICO, 2004; MACIEL, 2009.

5 "As exigências para a criação de Municípios foram, então, bastante abrandadas: a população mínima passou a ser igual à do Município de menor número de habitantes; consolidou-se a renda mínima igual a 5 milésimos por cento da arrecadação estadual; e o resultado do plebiscito, que antes era de 50\% mais 1 dos eleitores habilitados, baixou para 50\% mais 1 dos que houvessem comparecido, desde que estes totalizassem mais de 50\% do colégio eleitoral. Ou seja, com a nova matemática, a aprovação baixou para $25 \%$ mais 1 do universo total. (...) Tendo em vista experiências anteriores, vinculou o percentual de eleitores, em relação à população, em $20 \%$ (o dobro dos $10 \%$ previstos anteriormente na legislação federal); impediu a interrupção da continuidade territorial do Município de origem; dobrou para 400 o número mínimo de casas no centro urbano; impôs a preexistência de instalações próprias para o funcionamento dos órgãos públicos do novo Município; e estabeleceu que este tenha limites com pelo menos dois Municípios.” (NUNES, 1992: 20). 
De acordo com o jornalista Jorge Nunes, com a promulgação dessa nova lei:

As exigências para a criação de Municípios foram, então, bastante abrandadas: a população mínima passou a ser igual à do Município de menor número de habitantes; consolidou-se a renda mínima igual a 5 milésimos por cento da arrecadação estadual; e o resultado do plebiscito, que antes era de 50\% mais 1 dos eleitores habilitados, baixou para $50 \%$ mais 1 dos que houvessem comparecido, desde que estes totalizassem mais de $50 \%$ do colégio eleitoral. Ou seja, com a nova matemática, a aprovação baixou para $25 \%$ mais 1 do universo total. (...) Tendo em vista experiências anteriores, vinculou o percentual de eleitores, em relação à população, em $20 \%$ (o dobro dos $10 \%$ previstos anteriormente na legislação federal); impediu a interrupção da continuidade territorial do Município de origem; dobrou para 400 o número mínimo de casas no centro urbano; impôs a preexistência de instalações próprias para o funcionamento dos órgãos públicos do novo Município; e estabeleceu que este tenha limites com pelo menos dois Municípios (NUNES, 1992: 20).

O autor ressalta, ainda, que os avanços observados nas legislações federal e estadual forneceram dispositivos que, ao reforçarem o federalismo brasileiro, acabaram por facilitar o surgimento de novos municípios. Esses argumentos são apresentados no decurso de uma publicação para a Coleção Tiradentes, iniciativa da Assembleia Legislativa do Estado do Rio de Janeiro, sob a coordenação do deputado Paulo Duque. Esse deputado desempenhou papel de destaque no processo de emancipação queimadense, como se discutirá adiante. $\mathrm{O}$ quarto volume da coleção, de autoria de Nunes, é integralmente dedicado à criação dos novos municípios no Estado do Rio de Janeiro e foi publicado em 1992, portanto, ainda em plena efervescência dos movimentos emancipacionistas fluminenses, " como um "balanço" da atuação de Duque, nesse sentido.

Assim, amparados na nova legislação, os argumentos mobilizados nas falas das lideranças da AAPQ para defender a necessidade de emancipação recaem sobre o atraso de Queimados, na condição de Segundo Distrito de Nova Iguaçu. Tratava-se de buscar a legitimidade da emancipação, tomando como base aspectos identitários atrelados às configurações econômicas e sociais do local, em contraposição ao suposto descaso da administração iguaçuana. Nessa perspectiva, destacamos algumas falas:

Uma cidade com aspecto de pobreza absoluta, sem nenhuma expectativa do que hoje observamos a cidade. Não, não tinha nenhuma rua pavimentada. Nenhuma, nenhuma, nenhum aspecto de progresso, de desenvolvimento, não tinha. Era estrada de chão, de barro, conduzindo até a Pneus General. (...) A pavimentação, em Queimados, era da antiga padaria do Geraldo Xavier, onde tem uma passagenzinha, uma pontezinha ali, até a esquina, do final da praça... (MACEDO, 2009, grifos nossos)

Queimados era um distrito de Nova Iguaçu, não sei se Segundo Distrito, mas era muito atrasado, não tinha nada aqui, nem taxi, aqui não tinha! Tinha um carro preto que fazia um táxi, pra ajudar, mas nem achava o táxi, não tinha nada aqui. (...) As ruas. Muita lama, é, é, Queimados era muito atrasado mesmo, sabe? Não! Era o centro de Queimados mesmo! Só tinha uma rua de paralelepípedos ali, que é aquela principal do lado de cá, a, a Irmãos Guinle, a Tinguá: tudo, tudo era tudo terra, barro, entendeu? (MATTOS, 2012, grifos nossos)

Então ficava muito difícil, as coisas ficavam tudo em Nova Iguaçu, a gente tem que desenvolver Nova Iguaçu primeiro, para depois ir para periferia. É o que tá acontecendo em Queimados: nós estamos desenvolvendo o centro e estamos andando para o interior. E lá era assim, até chegar aqui você já tava morto e, e, não ia acontecer nada. Você, que é mais novo, eu já era, que já sou mais velho. Então isso que fomentou o abandono, o desleixo da cidade: a gente aqui largado de tudo quanto é maneira, gente morrendo aí sem saúde, sem nada. Que mal ou bem, hoje, você tem uma saúde

6 Destacamos que, entre os anos de 1985 a 1988, foram criados cinco novos municípios no estado do Rio de Janeiro Esses municípios são: Arraial do Cabo, desmembrado de Cabo Frio e criado pela Lei no 839, de 13 de maio de 1985; Italva, desmembrado de Campos e criado pela Lei n ${ }^{\circ}$ 999, de 12 de junho de 1986; Paty do Alferes, desmembrado de Vassouras e criado pela Lei no 1254, de 15 de dezembro de 1987; São José do Vale do Rio Preto, desmembrado de Petrópolis e criado pela Lei no 1255, de 15 de dezembro de 1987 e Itatiaia, desmembrado de Resende e criado pela Lei n 1330, de 06 de julho de 1988. De 1989 até 1992, outros doze municípios, entre esses Queimados, foram criados no estado do Rio de Janeiro: Quissamã, desmembrado de Macaé e criado pela Lei no 1419, de 04 de janeiro de 1989 ; Cardoso Moreira, desmembrado de Campos e criado pela Lei n ${ }^{\circ}$ 1577, de 30 de novembro de 1989; Belford Roxo, desmembrado de Nova Iguaçu e criado pela Lei no 1640, de 03 de abril de 1990; Guapimirim, desmembrado de Magé e criado pela Lei n ${ }^{\circ} 1772$, de 21 de dezembro de 1990; Queimados, desmembrado de Nova Iguaçu e criado pela Lei no 1773, de 21 de dezembro de 1990; Quatis, desmembrado de Barra Mansa e criado pela Lei n ${ }^{\circ}$ 1787, de 09 de janeiro de 1991; Varre-Sai, desmembrado de Natividade e criado pela Lei n 1790 , de 12 de janeiro de 1991; Japeri, desmembrado de Nova Iguaçu e criado pela Lei nº 1902, de 02 de dezembro de 1991; Comendador Levy Gasparian, desmembrado de Três Rios e criado pela Lei no 1923, de 23 de dezembro de 1991; Rio das Ostras, desmembrado de Casimiro de Abreu e criado pela Lei no 1984, de 10 de abril de 1992; Aperibé, desmembrado de Santo Antônio de Pádua e criado pela Lei n 1985 , de 10 de abril de 1992 e Areal, desmembrado de Três Rios e criado pela Lei no 1986, de 10 de abril de 1992 (Cf.: NUNES, 1992: 57-68, grifos nossos). 
que você pode dizer que tá 100\% em relação àquela época. Você não tinha nada, você tinha que levar para Nova Iguaçu ou lá para baixo e às vezes morria aqui mesmo. Não tinha uma casa de saúde, não tinha nada. Nós temos aí a Bom Pastor, hoje, nós queimadense podemos até não dar valor, mas ela é de grande valia para Queimados... (VILELA, 2012, grifos nossos)

Por exemplo: lá onde eu morava, que o Guilherme [primeiro filho do depoente] nasceu, é, a luz era de cabine, uma luz muito fraca, muito fraca, luz de cabine, o que era quase que comum aqui em Queimados, o uso de cabine. Você vê: ali é praticamente é centro, mas a luz de cabine. Imagine aí na periferia! As ruas, também não existiam ruas no sentido da pavimentação... (SANZ, 2012, grifos nossos)

Constatamos significativo grau de compreensão, por parte dos entrevistados, das discrepâncias do desenvolvimento social e econômico entre centro e periferia. Esse modelo de desenvolvimento não é característico da Baixada Fluminense somente. Ampliando a escala de observação, podemos entendê-lo como um modelo assumido ao nível nacional, desde a década de 1970, ainda sob o regime ditatorial. O historiador Alberto Aggio e a cientista política Maria D’Alva Kinzo ressaltam que, apenas nos primeiros anos do regime civil-militar, houve um esforço pela contenção das taxas de inflação e estabilização da economia. Nesse caso, o chamado "milagre brasileiro" teria sido produto dessa estabilização, posta em prática entre os anos de 1964 e 1967, e da política desenvolvimentista que, nesse contexto, consagrava o Estado na posição do grande empreendedor. Assim, se a década de 1970 assinalou um recrudescimento no aparelho repressivo do Estado, por outro lado, essa década também marcou a difusão da ideia do "milagre brasileiro". Tal premissa era pautada em uma política de desenvolvimento nacionalista, dando ênfase à industrialização brasileira, inicialmente à produção de bens de consumo. Posteriormente, em nítida articulação com o panorama mundial bipolarizado pela Guerra Fria, passou-se à produção de bens intermediários e de capital (AGGIO, 1996 e KINZO, 2001).

Um dos efeitos do "milagre" foram os investimentos pesados na industrialização da região sudeste do país, tornando muito atraentes os grandes centros urbanos aí localizados. No caso de Queimados, essa constatação encontra respaldo na análise da origem dos entrevistados: no total de oito entrevistas, apenas um depoente é oriundo da Baixada Fluminense, tendo nascido no município de Nova Iguaçu, do qual Queimados era distrito. ${ }^{7}$ Contudo, a família desse depoente, bem como os demais entrevistados, são provenientes da região nordeste e do próprio interior da região sudeste, inseridos no contexto mais amplo das grandes migrações, motivadas pela seca e pelo recrudescimento das disparidades sociais no interior do Brasil, dirigindo-se a cidades como Rio de Janeiro e São Paulo. Essa dinâmica de migração interna possui dupla face: por um lado, o esvaziamento das zonas rurais e, por outro, o inchaço e o crescimento desordenado dessas grandes cidades. Forma-se, então, um movimento encadeado que tende a reforçar e reproduzir tais condições socioeconômicas, posto que, se a migração se justifica a partir do recrudescimento das desigualdades sociais, em regiões interioranas e com carência de investimentos por parte dos governos, ela aprofunda essas desigualdades nas grandes cidades, onde os recursos e as oportunidades estão longe de contemplar todos. No que concerne a Baixada Fluminense, região que, pela proximidade com o município do Rio de Janeiro, tende a absorver esse transbordo populacional, o fenômeno da migração é objeto de discussão na pesquisa do geógrafo Marcus Rosa Soares. Segundo esse autor, notadamente a partir da década de 1950, com a decadência da citricultura na Baixada Fluminense,

Os novos moradores que se dirigiam para a região, em sua maioria, eram migrantes que estavam à procura de melhores condições não de vida, mas de sobrevivência com relação às adversidades de suas regiões de origem. Grande parte desses migrantes são oriundos de estados da região Nordeste [sic], do Espírito Santo e de Minas Gerais (SOARES, 2000: 71).

Assim como Soares, o também geógrafo Manoel Simões contemplou em suas pesquisas o estudo dos fenômenos que envolvem a construção das identidades geopolíticas na Baixada Fluminense, pautado nessas questões. Na percepção de Manoel Simões, a precariedade de recursos, que se constatava então, foi responsável pelo estreitamento de redes de sociabilidade que, desde esse momento, passaram a aglutinar parentes, amigos, vizinhos, em prol de melhorias para a localidade e a construção de habitações. Concordamos com o

7 No decurso de sua fala, Ismael Lopes de Oliveira revela que os pais chegaram a Queimados pouco antes de seu nascimento, vindos do nordeste, a convite de um tio, já estabelecido em Nova Iguaçu. 
autor, que afirma que a formação e a consolidação dessas redes foram fundamentais para a formação de um tipo embrionário de identidade que, mais tarde, foi significativo para as reivindicações emancipacionistas ${ }^{8}$ (SIMÕES, 2006: 125-132).

De fato, se nas memórias das lideranças entrevistadas predominam narrativas que atribuem a migração e o assentamento em Queimados aos fatores econômicos e sociais, ${ }^{9}$ há destaque também para os laços de amizade, como nos permite entrever a fala de Luiz Alonso:

Com o tempo, eu fui criando conhecimento com amizades aqui, que eu fui me afastando lentamente do Estácio. Até que chegou a um ponto que deixei de ir sábado e domingo. Creio até que eu deixei de ir para o Estácio em função do futebol, eu passei a jogar bola aqui em clubes em Queimados e com isso fui me afastando do, de sábado e domingo no Estácio. (...) Quando você fala impressão [sobre Queimados, na década de 1960], eu tenho que puxar ou buscar na memória. Mas naquela ocasião era até uma festa você sair do Estácio e vir em Queimados. Era uma festa! (...) Se você parar e colocar na tela da sua imagem: Queimados antigo e o Queimados de hoje, há, substancialmente uma mudança, mas há aquelas saudades que você tem... (SANZ, 2012)

Tal constatação é expressa na fala desse entrevistado, na medida em que suas memórias sobre Queimados, comparadas aos relatos dos outros sete depoentes, introduzem aspectos menos críticos e mais saudosistas em relação ao passado. Contudo, a partir da análise dessas informações, pode-se depreender que as condições precárias contribuíram para a formação de cidades-dormitórios que caracterizou e, em grande medida ainda caracteriza, parte das cidades da Baixada Fluminense. ${ }^{10}$ Mesmo em meados da década de 1970, quando a repercussão da crise mundial do petróleo afetava o Brasil e os evidentes sinais de "crise do milagre," as mesmas políticas econômicas se mantiveram, entretanto, como destaca, mais uma vez, Alberto Aggio, "a modernização vivida pelo País nestas três décadas fez com que agravassem velhas contradições sociais, ao mesmo tempo que engendrou outras tantas de natureza novíssima” (1996: 55). O autor assinala, entretanto, alterações na estrutura demográfica do Brasil, que deixava de ser, paulatinamente, um país agrário. O desenvolvimento da Baixada Fluminense e sua desordenada urbanização nesse período é sintomático do acirramento das desigualdades sociais, mantidas por esse modelo de "modernização conservadora".

Assim, em face de tal contexto, inferimos, no processo de construção das memórias dos entrevistados, a elaboração de uma imagem de si que demarcasse Queimados em oposição ao outro, representado por Nova Iguaçu. Ao desenvolver o conceito de outro, o sociólogo Michael Pollak pressupõe que "ninguém pode construir uma autoimagem isenta de mudança, de negociação, de transformação em função de outros" (POLLAK, 1992: 204). Tendo em vista as tensões políticas e econômicas postas em evidência pelo processo de transição democrático brasileiro, acreditamos que o estabelecimento de critérios de alteridade tenha sido a primeira estratégia utilizada, consciente ou inconscientemente, pelas lideranças, no intuito de reivindicar a emancipação. ${ }^{11}$

Ao definir Queimados, em relação ao outro, Nova Iguaçu, a ênfase recai sobre os poucos investimentos públicos locais. Expressões como pobreza absoluta, nenhum aspecto de progresso ou desenvolvimento, muito atrasado, precário, totalmente abandonado, desleixo e largado são utilizadas pelos depoentes para caracterizar Queimados, a partir de suas lembranças, quando lá chegaram. Esse ressentimento teve ocasião para vir à tona, depois de mais de duas décadas de silenciamento, imposto pela repressão intrínseca ao regime autoritário. Por outro lado, identificamos também o

8 "Assim, a autoconstrução pode vir a ser o embrião de movimentos sociais mais organizados, como os das associações de moradores que deram origem ao MAB no final dos anos de 1970 na Baixada Fluminense.” (SIMÕES, 2006: 131)

9 Nos depoimentos de Luiz Gonzaga de Macedo, Maria de Fátima Barragán, José Methódio Lima, Valtecir Gomes Leal, Carlos de França Vilela e Josias de Souza Mattos, a questão da migração, orientada pela busca de melhores condições de vida, é citada explicitamente. Em Ismael Lopes de Oliveira, a questão é apenas sugerida, quando este depoente afirma que seus pais chegaram a Queimados a partir do convite de um tio, que já havia se estabelecido em Nova Iguaçu há muito tempo.

10 Segundo o geógrafo Marcus Rosa Soares, cidades-dormitórios “são aquelas cidades onde a maior parte de sua população trabalhadora se desloca de suas periferias em direção às áreas comerciais e industriais localizadas em outro município. Este fluxo migratório corresponde às chamadas migrações pendulares, realizadas cotidianamente por milhares de trabalhadores brasileiros.” (2000: 74)

11 "Esse último elemento da memória - a sua organização em função das preocupações pessoais e políticas do momento - mostra que a memória é um fenômeno construido. Quando falo em construção, em nível individual, quero dizer que os modos de construção podem tanto ser conscientes como inconscientes" (POLLAK: 1992: 204, grifos do autor). 
uso de signos da modernização e progresso postulados pela ordem instituída, apropriados como forma de adicionar argumentos que sustentassem os discursos emancipacionistas. Assim, à construção negociada da identidade queimadense em oposição àquela iguaçuana, foi acrescido o argumento da arrecadação fiscal obtida com a instalação do citado Parque Industrial, ao final da década de 1970. A fala de Josias Mattos e Luiz Gonzaga de Macedo são, mais uma vez, emblemáticas para a construção desse discurso:

Queimados, rapaz, tinha uma renda muito grande, o Parque Industrial tinha vinte e tantas indústrias de médio e grande porte em Queimados. Lá. Lá. Hoje eu não sei como está. Queimados tinha uma renda muito grande. Então, eu tenho até, eu tenho o Diário Oficial que foi publicado. Por isso que digo pra vocês que eu fiz trabalho junto com a Secretaria de Governo do Estado de, de Finanças, eu tenho, eu tenho, em algum lugar aqui em casa a cópia do Diário Oficial que diz isso aqui, que faz que se nos tivesse mais quinze décimos de rendimento não passaria, porque abalaria o, as finanças do município mãe (MATTOS, 2012).

Só foi possível a independência de Queimados, motivada pela estrutura que se criou dentro do distrito, Segundo Distrito que era Queimados, e foi o Distrito Industrial e essas duas fábricas ali, que potencializou de tal ordem, trouxe o mercado financeiro pra cá. (MACEDO, 2009).

Dessa forma, os protestos emancipacionistas se alimentavam de argumentos que relacionavam Queimados ao desenvolvimento e ao progresso, na medida em que essa expressiva arrecadação não se revertia em melhorias locais. Como afirmou Carlos Vilela, os recursos eram, primeiramente, aplicados na sede do município, restando muito pouco ou quase nada para os distritos mais afastados, em um mecanismo local de reprodução da lógica que, como visto, vigorava ao nível estadual e federal. Ao evocar e difundir tal premissa, as lideranças davam o primeiro passo no sentido de construção de uma identidade queimadense: delimitavam sua alteridade diante de Nova Iguaçu. Essa é uma das chaves para a compreensão do movimento emancipacionista queimadense, bem como as memórias elaboradas por suas lideranças, mais de duas décadas depois da emancipação, entretanto, certamente, não é a única.

Embora o município de Queimados tenha passado a existir como entidade politicamente autônoma a partir da eleição da primeira prefeitura no pleito de 1991 e empossada em 1992, acreditamos que ainda há um longo caminho a ser percorrido, no sentido de construir possibilidades para uma identidade queimadense. Um exame minucioso das falas dos entrevistados, nos leva a pensar que tais identidades extrapolam as questões socioeconômicas, evocadas no começo do movimento. Além disso, trata-se de um processo de contínua construção, que não se esgotou quando da emancipação, em 1990.

Assim, a partir da ancoragem no arcabouço teórico proposto por Michael Pollak em conjunto com a aplicação da leitura das narrativas, proposta por Arfuch, buscamos, no decorrer dessa pesquisa, contemplar outras questões, atinentes ao processo de enquadramento das memórias. Por entender o trabalho de enquadramento da memória como um processo permanente e aberto a contínuas negociações, admitimos que, no caso queimadense, esse fenômeno venha se desdobrando em dois momentos-chave: o primeiro, quando as memórias subterrâneas das elites locais foram mobilizadas e enquadradas para legitimar a emancipação frente à Nova Iguaçu. O segundo, em pleno desenvolvimento, revela as disputas em torno das testemunhas autorizadas (POLLAK, 1989: 10) a narrar os fatos que envolveram o movimento emancipacionista: quais nomes devem ser lembrados e quais devem ser silenciados? Que fatos são relevantes e quais devem ser esquecidos? Por quê?

Ao esboçarmos respostas para esses questionamentos, adentraremos o terreno sensível das divergências pessoais e/ou político-partidárias. Dar conta dessas questões, certamente, faz parte das nossas indagações e se constitui no grande desafio dessa pesquisa. Igualmente, nos interessa investigar os possíveis porquês para o interesse renovado por deixar registradas suas memórias pessoais, manifesto pelos entrevistados. Os trabalhos de memória se desdobram em múltiplas direções, em contínua construção, apontando para experiências que estreitam cada vez mais suas relações com a história e suas possibilidades de escrita.

\section{Entrevistas:}

BARRAGÁN, Maria de Fátima de Oliveira. Entrevista concedida a Nilson Henrique de Araújo Filho. Nilópolis, 13 nov. 2009. 
LEAL, Valtecir Gomes. Entrevista concedida a Nilson Henrique de Araujo Filho. Queimados, 07 nov. 2009.

LIMA, José Methódio. Entrevista concedida a Nilson Henrique de Araujo Filho. Queimados, 04 nov. 2009.

MACEDO, Luiz Gonzaga de. Entrevista concedida a Nilson Henrique de Araujo Filho. Queimados, 31 out. 2009.

MATTOS, Josias de Souza. Entrevista concedida a Claudia Patrícia de Oliveira Costa e Nilson Henrique de Araujo Filho. Queimados, 07 abr. 2012.

OLIVEIRA, Ismael Lopes de. Entrevista concedida a Claudia Patrícia de Oliveira Costa e Nilson Henrique de Araujo Filho. Queimados, 16 mai. 2013.

SANZ, Luiz Alonso. Entrevista concedida a Claudia Patrícia de Oliveira Costa e Nilson Henrique de Araujo Filho. Queimados, 21 abr. 2012.

VILELA, Carlos. Entrevista concedida a Nilson Henrique de Araújo Filho. Queimados, 15 abr. 2012.

\section{Referências bibliográficas}

AGGIO, Alberto. (2013). Regime militar e transição democrática: um balanço do caso brasileiro. In Revista Estudos de Sociologia, v. 1, nº 1. Disponível em: www.seer.fclar.unesp.br/estudos/issue/view/121 Acessado em 20/04/2013.

ARAÚJO FILHO, Nilson H. de. (2010). Emancipação do município de Queimados: breve ensaio. Niterói, RJ. Monografia de Especialização: Lato Sensu em História do Rio de Janeiro/UFF.

ARFUCH, Leonor. (2010) O Espaço Biográfico: dilemas da subjetividade contemporânea. Trad.: Paloma Vidal. Rio de Janeiro: Eduerj.

ARTURI, Carlos S. (2001). O debate teórico sobre mudança de regime político: o caso brasileiro. In Revista de Sociologia e Política - Dossiê Transição Política. n. 17, Curitiba, Nov. - p.p.: 11-31.

AVRITZER, Leonardo. (1995). Cultura política, atores sociais e democratização: uma crítica às teorias da transição para a democracia. In: Revista Brasileira de Ciências Sociais, Belo Horizonte, MG, v. 10, n.28. Disponível em: www.anpocs.org.br/portal/publicações/rbcs_00_28/rbcs28_09.htm Acessado em $27 / 06 / 2012$.

CATROGA, Fernando. (2001). Memória, História e Historiografia. Coimbra: Quarteto Editora, 2001.

CODATO, Adriano Nervo. (2005) Uma história da transição brasileira: da ditadura militar à democracia. In Revista de Sociologia e Politica, Curitiba, 25, nov. - p.p.: 83-106.

FICO, Carlos. (2004) Versões e controvérsias sobre 1964 e a ditadura militar. In Revista Brasileira de História. São Paulo, v. 24, no 47. - p.p: 29-60. Disponível em: http://www.scielo.br/pdf/rbh/v24n47/a03v2447. pdf. Acessado em 23/04/2013.

HALBWACHS, Maurice. (1990). A memória coletiva. São Paulo: Vértice.

JELIN, Elizabeth. (2002). Los trabajos de la memória. Colección Memorias de la Represión. Buenos Aires: Siglo XXI Editores.

KERBAUY, Maria Teresa M. (1999). Transição democrática: a difícil construção da cidadania. In Perspectivas, São Paulo, 22. - p.p.: 129-136.

KINZO, Maria D’Alva G. (2001). A democratização brasileira: um balanço do processo político desde a transição. In São Paulo em perspectiva, v. 15, no 4, out/dez. Disponível em: www.scielo.br/pdf/spp/v15n4/10367.pdf Acessado em 13/04/2013. 
Artigos

MACIEL, David. O transformismo na substituição da institucionalidade autoritária pela institucionalidade democrática (1985-1990) In Projeto História, São Paulo, no 38, jun. - p.p.: 79-95.

NORA, Pierre (org). (1984). Les lieux de mémoire. Paris: Gallimard.

NUNES, Jorge C. P. (1992). Criação de Municípios no novo Estado do Rio de Janeiro. Coleção Tiradentes, Vol.: 04. Rio de Janeiro: ALERJ.

POLLAK, Michael. (1989) Memória, esquecimento, silêncio. In Estudos Históricos. Rio de Janeiro, Vol.: 2, $\mathrm{n}^{\mathrm{o} .:}$ 3. - p.p.: 3-15. $200-212$.

. (1992) Memória e identidade social. In Estudos Históricos. Rio de Janeiro, Vol.: 5, nº.: 10. - p.p.:

PUJOL, Javier Gil. (19983). Notas sobre el estudio del poder como nueva valoración de la historia política. In Pedralbes, no 3, Barcelona. - p.p.: 61-88.

SIMÕES, Manoel Ricardo. (2006). A cidade estilhaçada: Reestruturação Econômica e Emancipações Municipais na Baixada Fluminense. Niterói, RJ. Tese de Doutorado PPGG/UFF.

SOARES, Marcus Rosa. (2000). Ordens, desordens e contra ordens territoriais em Queimados - RJ. Niterói, RJ. Dissertação de Mestrado. UFF/PPG.

THOMPSON, Paul. (1992). A voz do passado: História Oral. Rio de Janeiro: Paz e Terra. 